\title{
Functional morphology of the trunk and paw pad skin of the African palm squirrel (Epixerus ebii)
}

\author{
C.S. Ibe ${ }^{1}$, A. Elezue ${ }^{2}$, E. Ikpegbu ${ }^{3}$ and U.C. Nlebedum ${ }^{4}$ \\ Department of Veterinary Anatomy, Michael Okpara University of Agriculture Umudike, Nigeria \\ ${ }^{1}$ ibe.chikera@mouau.edu.ng, ${ }^{2}$ richceecee@yahoo.com, ${ }^{3}$ ikpegbu.ekele@ mouau.edu.ng, ${ }^{4}$ nlebedum.uchenna@mouau.edu.ng
}

(Received August 28, 2019; Accepted December 3, 2019; Available online July 27, 2020)

\begin{abstract}
The study was initiated to contribute to the meager knowledge of the anatomy of the African palm squirrel. Skin of the trunk and paw pads was the subject of interest. Basic gross and histological techniques were employed. The dorsal fur was grey with golden brown free endings, while the ventral fur was greyish white. The fur covered the entire trunk, extended through the dorsal surface of the distal carpal joint to the dorsal surface of the digits. Five digital pads, three inter-digital pads and two metacarpal pads were observed on the forefoot. There was no observable digital pad on the hind foot; four inter-digital and two metacarpal pads were observed. Surface grooves were evident in the cornified layer of the trunk skin, but not in the paw pad skin. The mean thickness of the cornified layer of the epidermis of the palmar pad was $75.54 \pm 3.45 \mu \mathrm{m}$, while the entire epidermis was $102.32 \pm 4.23 \mu \mathrm{m}$ thick. The non-cornified layer of the trunk skin was made of only three distinct layers, as the stratum lucidum was not evident. Conversely, the stratum lucidum was evident in the paw pad skin. Dermal papillae observed in the paw pad skin were more numerous and progressed deeper into the non-cornified epidermis than those observed in the trunk skin. There were more melanocytes in the dorsal than in the ventral trunk skin. The study concluded that the trunk and paw pad skin of the African palm squirrel enable its adaptation to arboreal habitat.
\end{abstract}

Keywords: Dermal papillae, Keratinocyte, Paw pad, Skin, Squirrel

DOI: 10.33899/ijvs.2019.126047.1216, ( ) 2020, College of Veterinary Medicine, University of Mosul.

This is an open access article under the CC BY 4.0 license (http://creativecommons.org/licenses/by/4.0/).

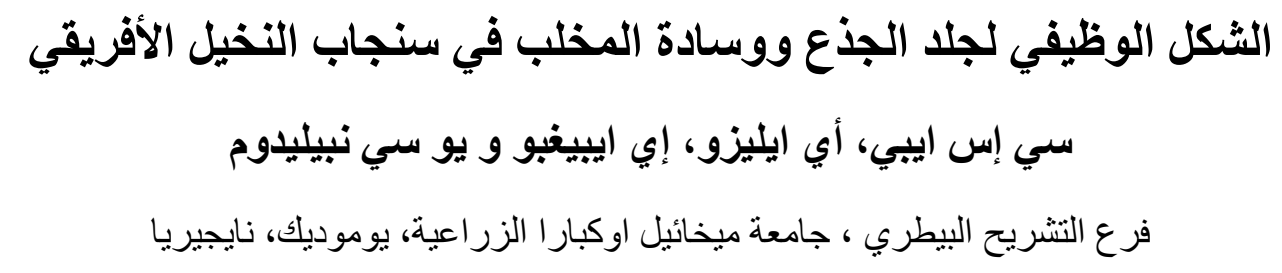

الخلاصة

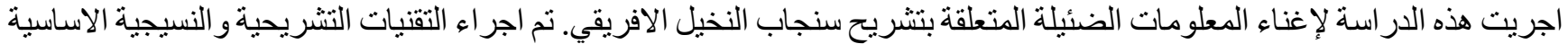

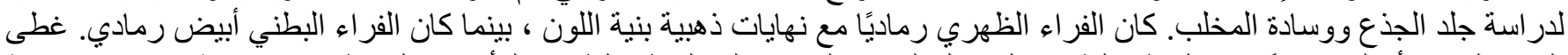

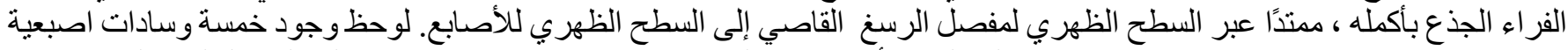

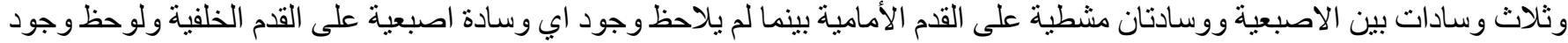

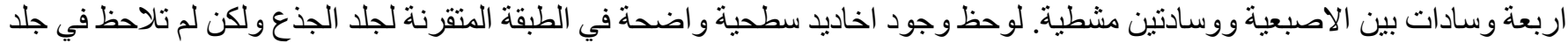

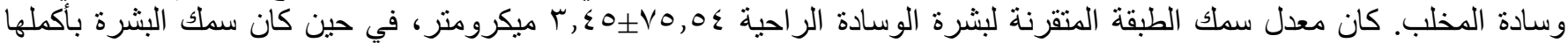

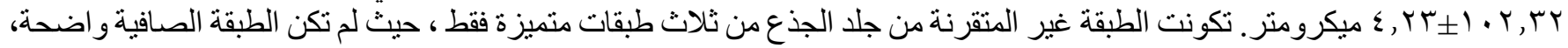

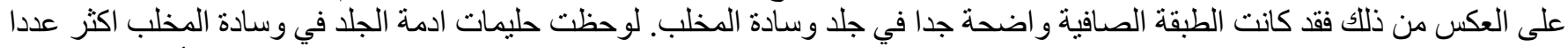

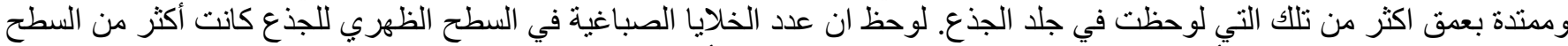
البطني. وخلصت الدر اسة إلى أن جلد جذع ووسادة مخلب سنجاب النخيل الأفريقي يتيح تكيفه مع الطبيعة التي تحتوي الني على اشجار. 


\section{Introduction}

Squirrels are rodents belonging to the family Sciuridae. They have been grouped into flying squirrels, arboreal squirrels and ground squirrels. There are about 285 species of squirrels worldwide, details of which have been documented by Thorington et al. (1). Of these, Akoma et al. (2) reported nine species in Gabon, whose habitat vary from ground to forest canopies. Epixerus ebii is an unstriped arboreal rainforest squirrel distinct by its bushy tail. It is the only specie of the genus Epixerus, but made of 3 sub species, Epixerus ebii ebii, Epixerus ebii jones iand Epixerus ebii wilsoni (3). It is indigenous to West Africa. In Nigeria, it dominates the squirrels in the South, where it is found jumping from one palm tree to another, in search of palm nuts. They are involved in forest regeneration through their seed dispersal activities. They are also classified as bush meat.

The integument connects the animal with the external environment and protects underlying organs from mechanical trauma and infection. Several studies have shown that the rodent integumentary properties are habitatspecific, and vary even for rodents of the same genus but diverse habitats (4-6). In the light of this, the present study aims to describe the gross and histologic structures of the trunk and paw pad skin of the African palm squirrel in relation to its habitat. The study also tests the hypothesis that the morphology of the trunk and paw pad skin of the African palm squirrel is related to its adaptation.

The present study will be indispensable in future dermatoglyphic studies in the African squirrel, aid wildlife biologists and conservationists in understanding the squirrel's adaptive physiology and guide veterinarians in managing paw pad and skin diseases in this specie. Results of the present study were also compared with that of other rodents in available literature, to add to the growing archive of comparative rodent anatomy.

\section{Materials and methods}

\section{Animals}

The sample consisted of seven clinically healthy adult African palm squirrels (Epixerus ebii-Temminck, 1853), obtained from the wild in Umudike, Abia State Nigeria, using locally made, non-traumatic traps. They were housed in the Histology/Embryology Laboratory of the Department of Veterinary Anatomy, Michael Okpara University of Agriculture Umudike, where the experiment was conducted. They were acclimatized for 1 month prior to the experiment. Palm fruits, yam peels, potatoes, concentrates and drinking water were made available ad libitum.

\section{Ethical note}

The experimental protocol and permission to euthanize the animals for research purpose was approved by the Research Ethics Committee of the College of Veterinary Medicine, Michael Okpara University of Agriculture Umudike, Nigeria. Management of the experimental animals was as stipulated in the Guide for the Care and Use of Laboratory Animals, $8^{\text {th }}$ edition, National Research Council, USA (National Academic Press, Washington).

\section{Experimental protocol}

The animals were sedated by intraperitoneal injection of $20 \mathrm{mg} / \mathrm{kg}$ Thiopental Sodium (Rotexmedica, Trittau, Germany) and immediately weighed using a digital electronic balance (Citizen Scales (1) PVT Ltd., sensitivity: $0.01 \mathrm{~g}$ ). Thereafter, they were euthanized with lethal dose of the same drug.

Gross anatomical features of the skin of the dorsal and ventral trunk and paw pads of the fore and hind feet were studied with the naked eyes. Photographs were obtained using a digital camera (Samsung NV100HD; 14.7 Megapixel). The maximum paw length was obtained as the distance from the middle of the line joining the proximal borders of the thenar and hypothenar pads to the base of the third digit, and value obtained with a centimeter rule. Paw width was obtained as the greatest radial to ulnar extent of the paw, measured with centimeter rule. The experimental procedures of Ibe $e t$ al. (5) were adopted for obtaining skin samples from the trunk and limbs for light microscopic examination and for histological preparation of the samples. The slides were stained with hematoxylin and eosin stains.

Histomorphometries of the trunk skin and paw pads were obtained using a calibrated ocular micrometer (LeitzWetzlar, Germany) following appropriate calibration of the light microscope with a stage micrometer (Graticules Ltd., London, U.K.). Photomicrographs were taken at x 100 and $\mathrm{x}$ 400 magnifications. Nomina Anatomica Veterinaria (7) was used for nomenclature.

\section{Analysis of data}

All metric data obtained were expressed as mean \pm SEM, and presented in tables and graphs. Values were subjected to one-way analysis of variance, followed by Turkey's post-hoc test to determine significance of the mean. Values of $\mathrm{P}<0.05$ were considered significant. GraphPad Prism version 4 (GraphPad Software Inc., San Diego, California) for Windows 8 , was used for the statistical analysis.

\section{Results}

\section{Gross anatomical features of the trunk skin}

The dorsal and ventral surfaces of the trunk of the African palm squirrel were shown (Figure 1). The fur on the dorsum was grey in color with golden-colored free endings. On the 
ventral surface of the trunk, it was greyish white in color. The fur covered the entire trunk. In the forelimb, it extended through the distal carpal joint on the dorsal surface, where the color was grey with golden free ending, to the entire dorsal surface of the digits, where the color became greyish white, as observed in the ventral surface of the trunk. The palmar surface of the metacarpus and digits lacked any visible hair. In the hindlimb, the fur extended to the dorsal surface of the digits. The fur color was grey with golden free endings up to the distal tarsal joint. It then became greyish white, up to the dorsal surface of the phalanges.

The plantar surfaces of the metatarsus and phalanges also lack hairs. Most of the scrotum and prepuce lacked hairs. The entire tail maintained same color of fur as was observed on the dorsal surface of the trunk. The shaved skin of the trunk was loosely folded. It was grey in color on the dorsal surface of the trunk, and greyish white in color on the ventral surface of the trunk.

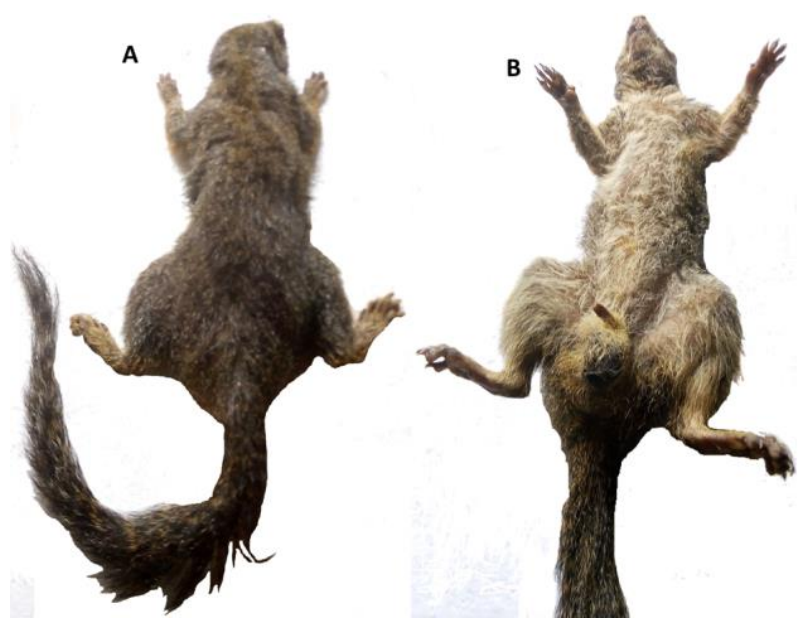

Figure 1: Dorsal (A) and ventral (B) fur of the African palm squirrel.

\section{Gross anatomical features of the palmar paw pads}

The palmar surface of the African palm squirrel was shown (Figure 2A). Five digital pads (I to V), three interdigital pads (B,C,D) and two metacarpal pads (E,F) were observed in the forefoot. Each digital pad was located on a digit. The second, third and fifth digital pads, located on the index, middle and small digits, respectively, were the largest, followed by the fourth digital pad. The first digital pad, located on the pollex, was the smallest digital pad. The first interdigital pad is lacking in the forefoot. The second interdigital pad (B), located between the second and third digits, was smaller than the third interdigital pad (C), but larger than the fourth interdigital pad (D). The third interdigital pad was located between the third and fourth digits, while the fourth interdigital pad was located between the fourth and the fifth digits. The metacarpal pads consisted of the hypothenar (E) and thenar (F) pads. The hypothenar pad was bigger than the thenar pad, and lay proximal to the fourth interdigital pad on its axis. Similarly, the thenar pad lay proximal to the second interdigital pad on an axis. The interdigital and metacarpal pads were arranged in a concentric circle. However, the hypothenar pad was more proximally inclined than the thenar pad. Flexion creases (black arrow) were observed on the palmar surface. The mean palmar paw length and width were $1.09 \pm 0.07 \mathrm{~cm}$ and $0.98 \pm 0.05 \mathrm{~cm}$, respectively.

\section{Gross anatomical features of the plantar paw pads}

The plantar surface of the African palm squirrel was shown (Figure 2B). There was no observable digital pad on the hindfoot. Four inter-digital pads (A, B, C, D) and two metatarsal pads (E, F) were observed. The first interdigital pad (A), located between the hallux and the second digit, was the largest interdigital pad. The second (B) and third (C) interdigital pads were of the same size and shape. The second was located between the second and third digits, while the third was located between the third and fourth digits. The fourth interdigital pad (D) was the smallest of the interdigital pads. It was located between the fourth and fifth digits. The metatarsal pads consisted of the hypothenar (E) and thenar (F) pads. The hypothenar pad was smaller than the thenar pad, and lay proximal to the fourth interdigital pad on its axis, while the thenar pad lay proximal to the first interdigital pad on its axis. The interdigital and metatarsal pads were arranged in a concentric circle, with the thenar pad being more proximal than the hypothenar pad. Flexion creases (black arrow) were also observed on the plantar surface. The claws were slightly curved, but not sickle shaped. The mean plantar paw length and width were $1.64 \pm 0.08 \mathrm{~cm}$ and $1.35 \pm 0.04 \mathrm{~cm}$, respectively. The difference between the palmar and the plantar paw lengths as well as the difference between the palmar and the plantar paw widths was significant $(\mathrm{P}<0.05)$.

\section{Histological features of the ventral trunk skin}

The microphotograph of the ventral trunk skin of the African palm squirrel was shown (Figure $3 \mathrm{~A}$ and $4 \mathrm{~A}$ ). The epidermis consisted of a very thin, undulating cornified layer (Figure 3A and 4A: a) and a non-cornified layer composed of keratinocytes. Surface groves were evident in the cornified layer (Figure 4A: b). The mean thickness of the cornified layer was $19.03( \pm 1.04) \mu \mathrm{m}$, while that of the entire epidermis was $45.93( \pm 1.23) \mu \mathrm{m}$. The non-cornified layer was made of three distinct layers. These were a single layer each of stratum basale (Figure 3A: d), stratum spinosum (Figure 3A: c) and stratum granulosum (Figure 3A: b). The stratum lucidum was not evident. Cells of the stratum basale were cuboidal or low columnar, with rounded nuclei, lying on a basement membrane above the superficial layer of the dermis. They separated the epidermis from the dermis. Cells 
of the stratum spinosum were polygonal while those of the stratum granulosum were squamous. The stratum granulosum separated the non-cornified from the cornified layer. Although numeric evaluation of the keratinocytes in the non-cornified layer was not done, the layer had scanty cells.

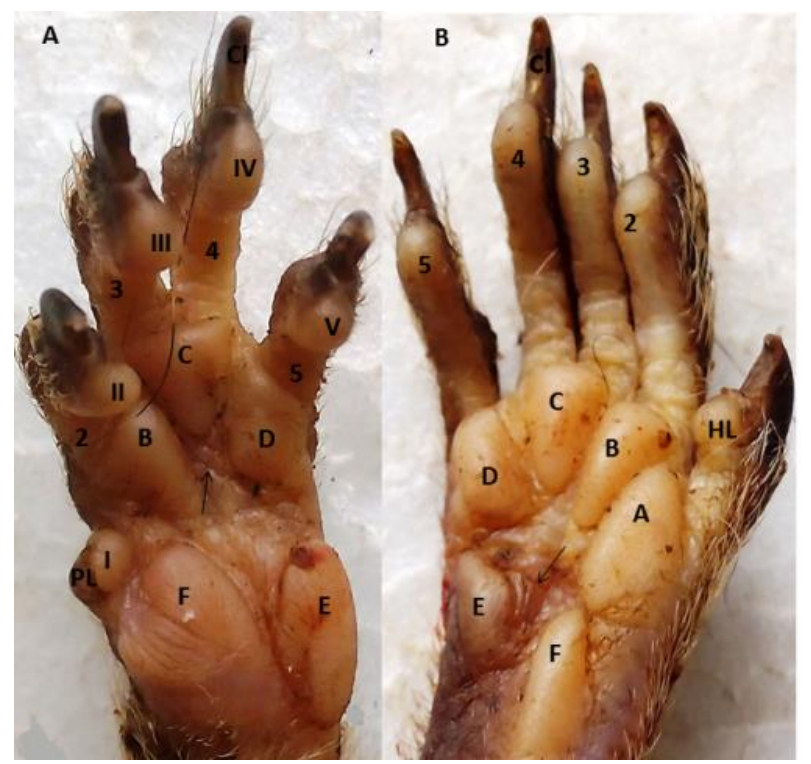

Figure 2: Palmar (A) and plantar (B) surfaces of the right and left feet, respectively, of the African Palm Squirrel. PL: Phallus; HL: Hallux; 2-5: Second to fifth digits; I-V: Digital pads; A-D: Interdigital pads; E: Hypothenar pad; F: Thenar pad; Black Arrow: Flexion caress.

In the dermis, very few dermal papillae (Figure 3A: arrow head) interdigitated with the non-cornified layer of the epidermis, resulting in indistinct epidermal ridges. The dermal papillae were blunt, did not progress extensively into the epidermis and were not close to each other. Simple hair follicles, occurring in clusters of two or three were evident in the superficial dermal layer (Figure 4A: c). Sinus hairs were not observed throughout the ventral trunk skin. Collagen fibres formed the bulk of the connective tissue in the superficial and deep layers of the dermis. Blood vessels were observed in the superficial and deep layers of the dermis. Sparse adipose cells (Figure 4A: f), characterized by clear cytoplasm and peripherally located nucleus, numerous sebaceous glands (Figure 4A: i), bounded by arrector pili muscle (Figure 4A: $h$ ), and nerve bundles were also observed in the deep layer of the dermis. Melanocytes were also observed in the same deep layer.

\section{Histological features of the dorsal trunk skin}

The microphotograph of the dorsal trunk skin of the African palm squirrel was demonstrated (Figure 3B and 4B).
The cornified layer of the epidermis was also thin, but not as undulating as that of the ventral trunk skin (Figure 3B and 4B: a). Surface grooves were evident in the cornified layer, similar to the ventral trunk skin (Figure 4B: b). The mean thickness of the cornified layer was $19.00( \pm 1.78) \mu \mathrm{m}$ while that of the entire epidermis was $40.82( \pm 1.02) \mu \mathrm{m}$. The difference in the thickness of the cornified layer of the dorsal and ventral skin was not significant $(P>0.05)$, but the difference in the thickness of the epidermis of the dorsal and ventral skin was significant $(\mathrm{P}<0.05)$. The non-cornified layer was also made up of a single layer each of stratum basale (Figure 3B: B1), stratum spinosum (Figure 3B:B2) and stratum granulosum (Figure 3B: b3). The stratum lucidum was not evident. The cellular structure of the stratum basale, stratum spinosum and stratum granulosum were as reported in the ventral trunk skin.

In the dermis, dermal papillae and epidermal ridges were not observed in most of the sections. Where they appeared, the interdigitation of the dermal papillae with the noncornified layer of the epidermis was very minimal. Simple hair follicles were observed. However, the hair follicles were relatively bigger in size and more numerous than those of the ventral trunk skin. These hair follicles were obliquely set in the superficial dermal layer (Figure 3B: C), anchored by arrector pili muscle tissue (Figure 3B: i). Sinus hairs were not evident. Blood vessels, adipose cells, sebaceous glands, nerve bundles and slipper-shaped skeletal muscle tissues (Figure 4B: g) were observed in the deep layer of the dermis. There were relatively more melanocytes than observed in the ventral trunk skin.

\section{Histological features of the palmar paw pad skin}

Microphotographs of the palmar interdigital pad of the African palm squirrel were shown (Figures 5A, 6A and 7). The cornified layer of the epidermis was of varied thickness. The mean thickness was $75.54( \pm 3.45) \mu \mathrm{m}$, while the mean thickness of the epidermis was $102.32( \pm 4.23) \mu \mathrm{m}$. Undulation of the layer was not marked. There were no observable surface grooves and papillary ridges in the layer. The non-cornified layer of the epidermis was made of keratinocytes at different stages of development (Figure 6A: b1-b4). Keratinocytes of the stratum basale were most numerous, low cuboidal to columnar in shape, each with distinct viable rounded nucleus. Above these were keratinocytes of the stratum spinosum which were polygonal in shape, with distinct nucleus. Above these were keratinocytes of the stratum granulosum, squamous to low cuboidal in shape, with granulated cytoplasm. The uppermost layer, just below the cornified layer, was the stratum lucidum. It was characterized by squamous shaped keratinocytes with either clear cytoplasm and pyknotic nucleus or clear cytoplasm devoid of nucleus. The number of keratinocytes decreased from the stratum basale to the stratum lucidum. 
In the dermis, very long dermal papillae interdigitating with the non-cornified layer of the epidermis constituted the papillary layer (Figure 5A: c). The interdigitation of the dermal papillae gave rise to epidermal ridges (Figure 5A: d). The dermal papillae were more numerous, of acute angle, progressed deeper into the non-cornified epidermis and very close to each other than was observed in the skin of the dorsal and ventral trunk. Numerous sweat glands were observed in the reticular layer (Figure 7). The glands were simple tubular, with mono-nucleated cuboidal secretory cells with distinct nuclei (Figure 7: d). The dark cells (Figure 7: e) opened into a secretory duct. Each secretory unit was bounded by a cell line of myoepithelial cells with squamous shaped nuclei (Figure 7: c). Numerous adipocytes of varied sizes, each characterized by a clear cytoplasm (Figure 7: a) and peripherally located nucleus (Figure 7: b) were evident in the reticular layer. Lobules of adipocytes were separated by bundles of collagen fibres (Figure 7: i). Nerve bundles, blood vessels and muscle tissues were also observed in the layer. There were no observable hair follicles.

\section{Histological features of the plantar paw pad skin}

Microphotographs of the plantar interdigital pad of the African palm squirrel were represented (Figures 5B and 6B).
The mean thickness of the cornified layer of the epidermis was $102.87( \pm 4.30) \mu \mathrm{m}$, while the mean thickness of the epidermis was $123.65( \pm 4.21) \mu \mathrm{m}$. The difference in the thickness of the cornified layer of the palmar and plantar interdigital pads was significant $(\mathrm{P}<0.05)$. Also, the difference in the thickness of the epidermis of the palmar and plantar interdigital pads was significant $(\mathrm{P}<0.05)$. The cornified layer was mildly undulating, without surface grooves, as observed in the palmar interdigital pad. There were no observable papillary ridges. Sweat gland ducts were identified in the cornified and non-cornified layers of the epidermis. The non-cornified layer was similar with that of the palmar interdigital pad.

The dermal papillae were less numerous, more blunt, shorter (or less progressive) and not close to each other than was observed in the palmar interdigital pad (Figure 5B: d). However, they were more interdigitating with the noncornified layer than those of the trunk skin. Numerous sweat glands and adipocytes, similar in form with those of the palmar interdigital pad, were identified. Nerve bundles, bundles of collagen fibers, blood vessels and muscle tissues were also observed in the layer. There were no observable hair follicles.
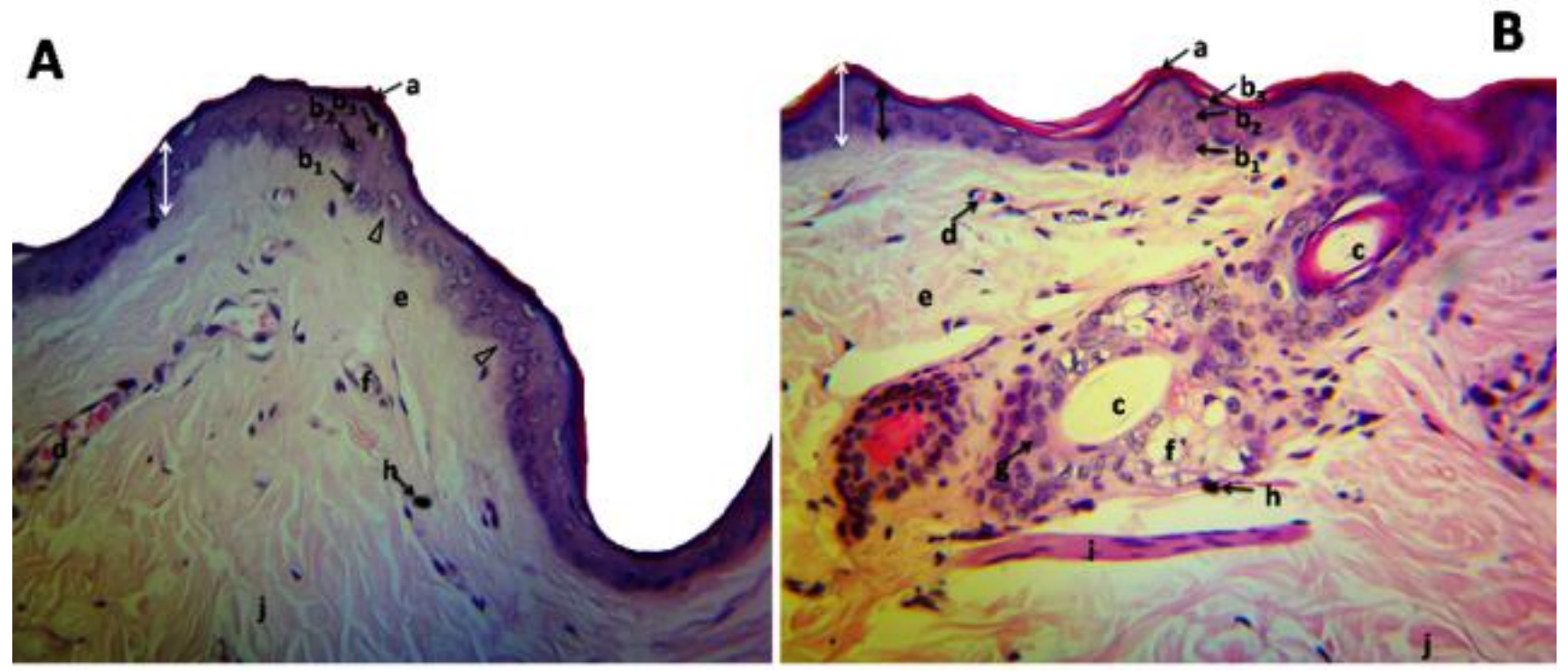

Figure 3: A coronal histological section of the ventral (A) and dorsal (B) trunk skins of the African palm squirrel at high magnification. White double arrow head: Epidermis; a: Cornified layer of epidermis; Black double arrow head: Non-cornified layer of epidermis; Arrow head: Dermal papillae; b3: Squamous cell of the stratum granulosum; b2: Polygonal cell of stratum spinosum; b1: Cuboidal to columnar cell of stratum basale; c: Hair follicle; d: Blood vessel; e: Collagen fibres of superficial dermis; f: Adipocyte; g: Sebaceous gland; h: Melanocyte; i: Arrector pili muscle; j: Deep layer of dermis $(\mathrm{bar}=40 \mu \mathrm{m})$. 

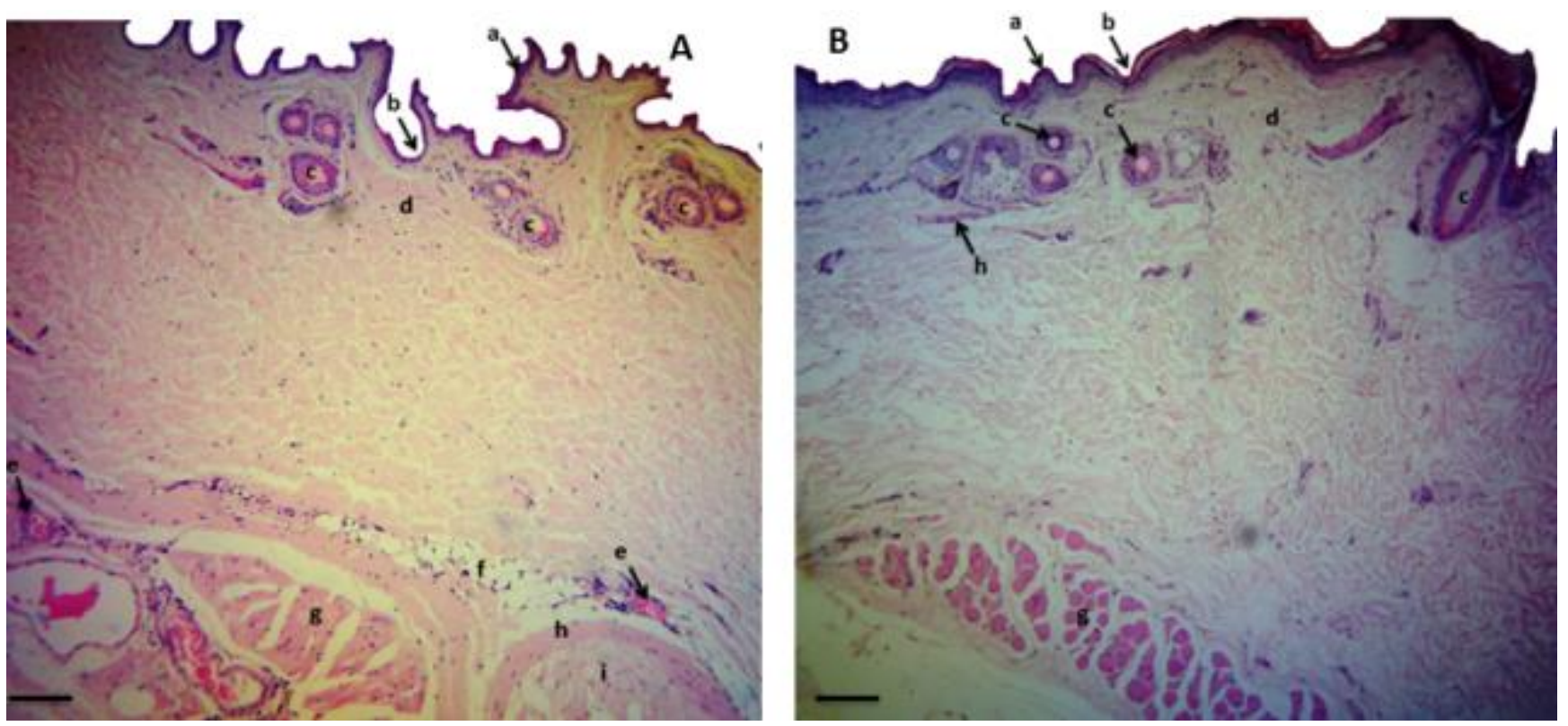

Figure 4: Coronal Histological Section of the Ventral (A) and Dorsal (B) Trunk Skins of the African Palm Squirrel at Low Magnification. a: Epidermis; b: Surface groove; c: Hair follicles; d: Collagen fibres of superficial dermis; e: blood vessels in deep dermis; f: Adipocytes; g: Muscle tissues; h: Arrector pili muscle; i: Sebaceous gland (bar $=10 \mu \mathrm{m})$.
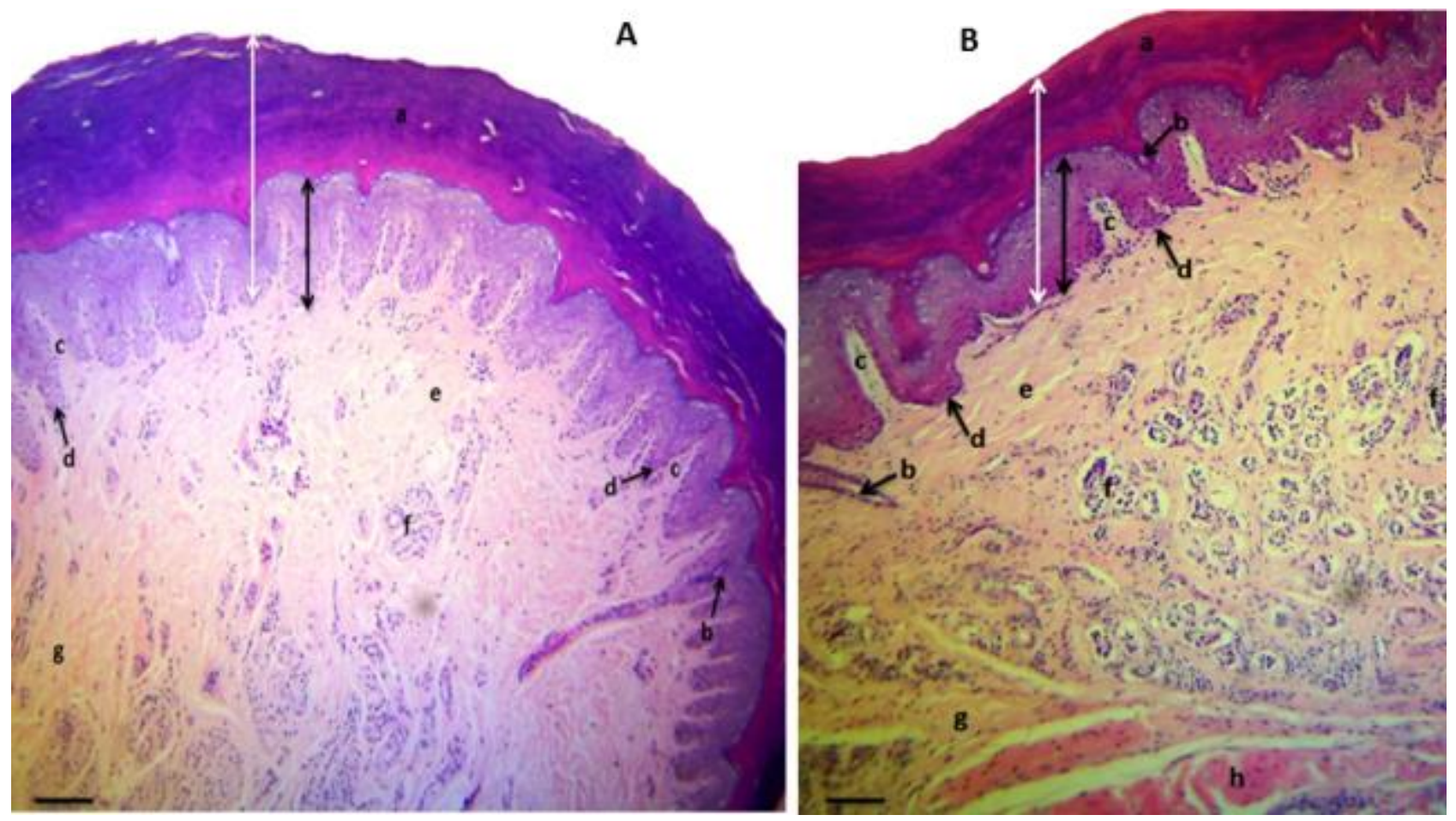

Figure 5: Coronal Histological Sections of the Palmar (A) and Plantar (B) Interdigital Pads of the African Palm Squirrel. White double arrow head: Epidermis; a: Cornified layer of epidermis; Black double arrow head: Non-cornified layer of epidermis; b: Duct of sweat gland; c: Papillary layer of dermis; d: Epidermal ridges; e: Reticular layer of dermis; f: Merocrine sweat glands; g: Interdigital cushion; h: Skeletal muscle $(\mathrm{bar}=10 \mu \mathrm{m})$. 

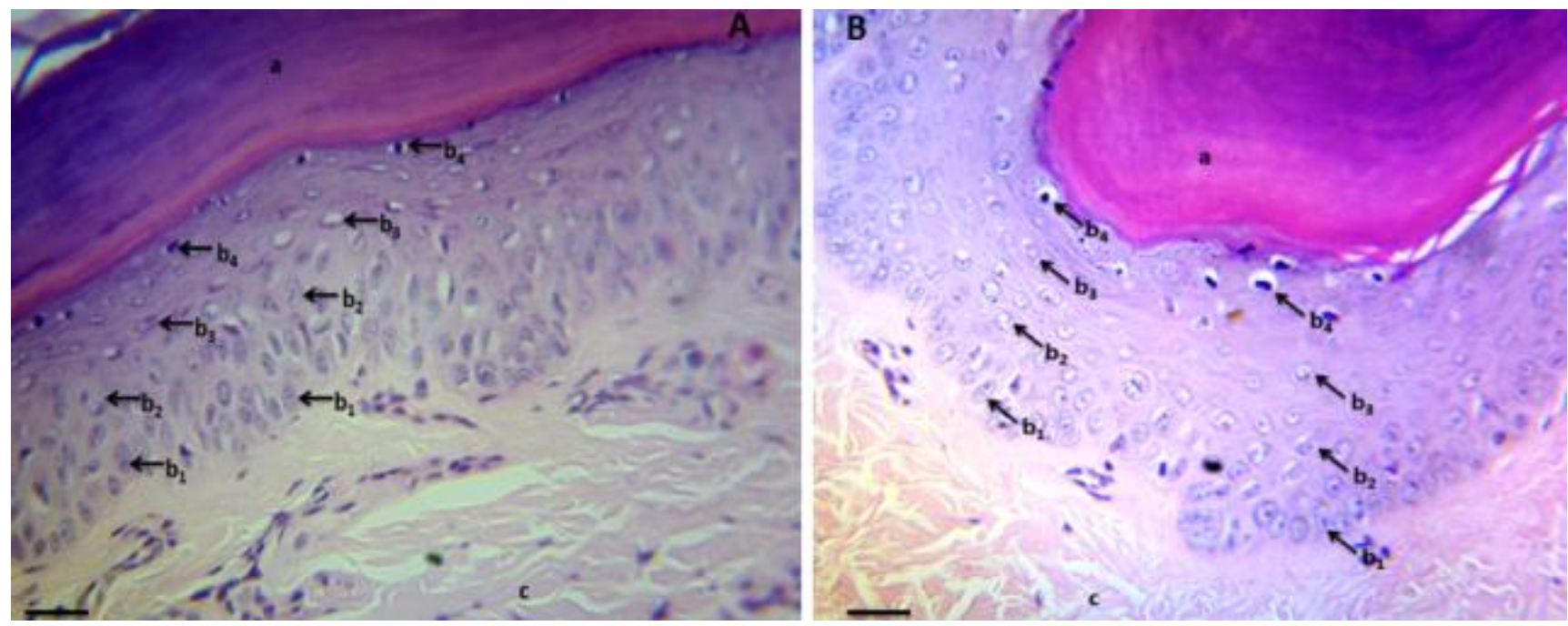

Figure 6: Coronal Histological Sections of the Palmar (A) Plantar (B) Interdigital Pads of the African Palm Squirrel at High Magnification. a: Cornified layer of epidermis; b1: Keratinocytes of the stratum basale; b2: Keratinocytes of the stratum spinosum; b3: Keratinocytes of the stratum granulosum; b4: Keratinocytes of the stratum lucidum; c: Collagen fibers of the dermis $($ bar $=40 \mu \mathrm{m})$.

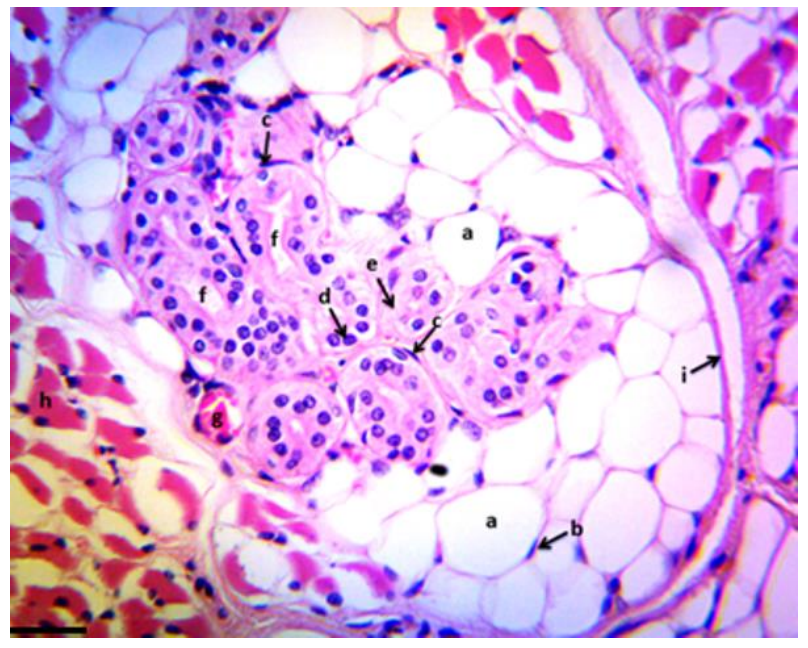

Figure 7: Microphotograph of the dermal reticular layer of the palmar interdigital pad of the African Palm Squirrel. a: Adipocyte; b: Nucleus of adipocyte; c: Myoepithelial cell nucleus; d: Secretory cell nucleus; e: Dark cell; f: Sweat gland duct; g: Capillary; h: Skeletal muscle; i: collagen fibres separating fat lobules $(\mathrm{bar}=40 \mu \mathrm{m})$.

\section{Discussion}

The grey colored dorsum observed in this study was similar to the chestnut gray to grizzled buff dorsum reported for the Caucasian squirrel, Sciurus anomalus by Koprowski et al. (8). This may be due to increased capillary supply and presence of more melanocytes in the dorsal than ventral skin, as observed in this study. Fur color of rodents depends on the habitat (9). Although the African palm squirrel is arboreal, they come down to the ground to forage for food (10). At such periods, the grey coloured dorsum camouflages with the rainforest, thus, enabling the squirrels evade predation. When on trees, the white colored ventrum camouflages with the sky, thus, 'hiding' the squirrels from predators' view. In line with the study of Wanner et al. (11), the numerous skin folds observed in histologic sections are indicative of a large surface area with resultant increased heat dissipation and cooling effect in the African squirrel.

In the present study, digital pads were observed in the forefoot, and not hindfoot of the African palm squirrel. Conversely, digital pads have been reported on the hindfoot of the Caucasian squirrel by Albayrak and Arslan (12). Being a good climber, it is expected that the African palm squirrel engages the forelimb to a more rigorous frictional activity than the hindlimb. This may explain the reason for the disparity. Ibe et al. (5) observed the presence of plantar digital pads and absence of palmar digital pads in the African giant pouched rat, unlike in the present study. The African giant pouched rat is a subterranean rodent which digs with the claws and uses the plantar pad to push excavated soil away (5). The broader plantar than palmar surface observed in this study may be compensatory for the lack of plantar digital pads. This is so as the broad planter surface will also increase friction during climbing. This is in line with the report of Akoma et al. (2) that arboreal rodents have broad feet. 
The numerous sweat glands and adipocytes scattered all over the dermis and hypodermis of the paw pads in the present study are thought to act as cushions and pressure bearers during the frictional activities engaged by the paw pads. The adipose tissues also have metabolic functions, serving as source for the production of vitamin D and triglycerides. The bundle of collagen fibres, sited in the reticular layer, also constituted a cushion for the paw pads. The absence of hair follicles places the paw pad skin in the glabrous class.

The African palm squirrel possessed short and blunt claws unlike most trunk climbers and other arboreal rodents that possess sharp claws as reported by Kingdon (13). These claws, though will assist in climbing, are probably disposed to be of less importance than the developed palmar digital and metacarpal pads in climbing. Long and sickle shaped claws have been reported in burrowing rodents such as the Anatolian mole rat (14) and the African giant pouched rat (5) which, according to the authors, assist the rodents in digging their burrows. The short, blunt and slightly curved claws of the African palm squirrel may be important in the even distribution of the animal's weight across the various diameter of the climbing surface. This is so, as the squirrels can quickly respond to the challenges they encounter as they move through wooded areas by instantly changing direction (15). This is a function of their claws' ability to shift their weight to find the center of gravity. The long tail helps the squirrel to balance and steer when jumping from tree to tree and running along branches.

Dermal papillae were more evident in the paw pads than in the skin of the trunk. Similarly, Tsugane and Yasuda (16) reported that the dermal papilla is more developed in paw pads than any other skin. The papillae function in anchoring the epidermal and dermal layers of the skin (17). This increased adhesion between the two layers is necessary to maintain the integrity of the skin to ensure protection against ultraviolet light, mechanical, thermal and chemical stresses, dehydration and microbial invasion (17). In the African palm squirrel, the frictional force exerted on the paw pad skin by the external environment threatens the protective function of this skin, in comparison with the skin of the trunk. This explains the observation of more developed dermal papillae in the paw pads than the trunk skin in the present study. Also, with the significantly thicker paw pad epidermis, than trunk skin epidermis, an increased surface area created by the dermal papillae is necessary for nutrient supply to the avascular epidermis. This may also be responsible for the more developed dermal papillae in the paw pads than in the trunk skin. However, the dermal papillae were observed to be more developed in the palmar than in the plantar paw pads, based on the sharpness of the angle, the extent of progress into the epidermis, the number and closeness of the papillae to each other. This, and the grossly observed palmar digital pads, instead of plantar digital pads, buttresses the hypothesis that the African palm squirrel subjects the palmar digits to tree grasping, more than the plantar digits.

Delmas et al. (18) demonstrated high concentration of Meissner's corpuscles, which are touch receptors, as well as non-myelinated free nerve endings in the mammalian dermal papillae. This implies that the dermal papilla is an efficient means of increasing the acuteness of the sense of touch. Its development in the palmar than plantar skin in the present study suggests that the sense of touch is more acute in the palmar than plantar skin in the African palm squirrel. This is expected, as the rodent engages the palmar digits more than the plantar digits in grasping, feeding and climbing.

\section{Conclusion}

The present study has provided some explanations to the adaptation of the skin of the trunk and paw pads of the African squirrel to climbing and hot tropical climate. Such idea is essential in conserving squirrel wildlife population and in the domestication of the rodent as there is a need to provide a near-natural habitat during breeding and domestication of the rodent.

\section{Acknowledgements}

The authors hereby acknowledge the efforts of the laboratory technologist, Mr. Agbakwuru, I., in the preparation of the histological slides.

\section{Conflict of interests}

The authors declare that there are no conflicts of interest regarding the publication of this manuscript.

\section{References}

1. Thorington RW, Koprowski JL, Steele MA, Whatton JF. Squirrels of the World. Baltimore: John Hopkins University Press; 2012. 427 p.

2. Akoma MR, Berge C, Picard N. Foot morphology and locomotor behavior of squirrels in Gabon rainforests. CR Biol. 2009;332:43-51. Doi: $10.1016 / j . c r v i .2008 .08 .020$

3. Thorington RW, Hoffmann RS. Family Sciuridae. Baltimore: Johns Hopkins University Press; $2005 . \quad 754-818 . \quad$ Doi: 10.1108/09504120610673024.

4. Mori E, Maggini I, Menchetti M. When quills kill: The defense strategy of the crested porcupine Hystrix cristata L. Mammalia. 1758;78:229234. https://doi.org/10.1515/mammalia-2013-0126

5. Ibe CS, Salami SO, Ajayi IE. Trunk and paw pad skin morphology of the African giant pouched rat (Cricetomys gambianus, Waterhouse1840). Euro J Anat. 2014;18(3):175-182.

6. Stewart E, Ajao MS, Ihunwo AO. Histology and ultrastructure of transitional changes in skin morphology in the juvenile and adult fourstriped mouse (Rhabdomys pumilio). Sci World J. 2016;20(1):1-11. https://doi.org/10.1155/2013/259680

7. Nomina Anatomica Veterinaria. International Committee on Veterinary Gross Anatomical Nomenclature, $6^{\text {th }}$ ed., Hannover, Columbia; 2017. $160-167 \mathrm{p}$. 
8. Koprowski JL, Gavish L, Doumas SL. Sciurus anomalus (Rodentia: Sciuridae). Mammalian. 2013; 48(934): 48-58. Doi: 10.1093/mspecies/sew004.

9. Gochis E. Thryonomys swinderianus [internet]. University of Michigan Museum of Zoology: Animal Diversity Web (cited 2002). Available from https://animaldiversity.org/accounts/Thryonomys_swinderianus/.

10. Thorington RW, Ferrel K. Squirrels. The animal answer guide. Maryland; the Johns Hopkins University press; 2006. 345 p.

11. Wanner SP, Prímola-Gomes TN, Pires W, Guimarães JB, Hudson ASR, Kunstetter AC, Fonseca CG, Drummond LR, Damasceno WC, Teixeira-Coelho F. Thermoregulatory responses in exercising rats: Methodological aspects and relevance to human physiology. Temp. 2015;2(4):457-475. 10.1080/23328940.2015.1119615

12. Albayrak I, Arslan A. Contribution to the taxonomical and biological characteristics of Sciurus anomalus in Turkey (Mammalia: Rodentia). Turk J Zool. 2006;30:111-116. 10.1093/mspecies/sew004
13. Kingdom J. On being a primate, from Gondwana to the forest of Egypt. New Jersey: Princeton University Press; 2003. 49 p.

14. Kryštufek B, Vohralík V. Mammals of Turkey and Cyprus. Koper: University of Primorska, Science and Research Centre of Koper Historical Society of Koper; 2009. 252-267 p.

15. Pettitt BA, Waterman JM, Wheaton CJ. Assessing the effects of resource availability and parity on reproduction in female Cape ground squirrels: Resources do not matter. J Zool. 2008;276(3):291-8. 10.1111/j.1469-7998.2008.00491.x

16. Tsugane M, Yasuda M. Dermatoglyphics on volar skin of mice: The normal pattern. Anat Rec. 1995;242:225-232. 10.1002/ar.1092420212

17. Blanpain C, Fuchs E. Epidermal stem cells of the skin. Annu Rev Cell Dev Biol. 2006;22:339-373. 10.1146/annurev.cellbio.22.010305.104357

18. Delmas P, Hao J, Rodat DL. Molecular mechanisms of mechanotransduction in mammalian sensory neurons. Nat Rev Neurosci. 2011;12:139-153. 10.1038/nrn2993 